\title{
Abuse-deterrent formulations: transitioning the pharmaceutical market to improve public health and safety
}

\author{
Kyle Simon, Stacey L. Worthy, Michael C. Barnes and Benjamin Tarbell
}

\begin{abstract}
This article evaluates abuse-deterrent formulations (ADFs) as a method to reduce prescription drug abuse while ensuring access to vital medications for individuals with legitimate need; assesses the pros and cons of ADFs and the current state of ADF adoption in the market; and develops policy recommendations to transition the market to ADFs. Although abuse-deterrent technology is still in its nascent stages, ADFs have been proven to reduce prescription drug abuse and its consequences, and even an incremental reduction in abuse can have a significant impact on the nation by reducing the costly social, physical, mental, and public health problems resulting from abuse. Federal ADF policy does not reflect the urgency of the prescription drug abuse epidemic and does not go far enough toward changing the status quo. Policies must be implemented to encourage innovation and a market shift toward ADFs by ensuring any generic medication that references a branded ADF demonstrates that it does not have abuse-deterrent properties inferior to the branded ADF product. Policies must also require federal prescription drug benefit plans to cover ADFs to ensure consumers have access to such medications.
\end{abstract}

Keywords: abuse-deterrent formulation, controlled substance, pharmaceuticals, prescription drug abuse, substance abuse, substance use disorders

\section{Introduction}

When Sean Watkins, of Rockcastle, Kentucky, was 10 years old, his mother failed to show up for dinner one night. Searching for her, he found her face down and motionless in her bedroom. She had died of an oxycodone overdose, leading Sean to move in with his grandmother. Soon after, his grandmother also became addicted to prescription drugs and eventually abandoned him. $\mathrm{He}$ now lives with his grandfather. In Kentucky, Sean is one of more than 86,000 children who have lost a parent to prescription drug abuse. In Knott County alone, it is estimated that more than half of the children there have lost their parents, and in nearby Johnson County, so many children have lost parents that school administrators changed "Parents' Day" to "Guardians' Day" [Smith and Kounang, 2013].

Prescription drug abuse affects Americans of all ages, education, income level, gender, and ethnic background. In 2012, approximately 2.4 million people aged 12 or older abused prescription drugs, including pain relievers, tranquilizers, stimulants, and sedatives, for the first time [SAMHSA, 2013a]. Of those, 1.9 million individuals began abusing prescription opioids, medications used to treat moderate to severe pain [SAMHSA, 2013a]. Although prescription opioid abuse results in the deaths of 46 people per day in the U.S. [SAMHSA, 2011; CDC, 2014a] an estimated 100 million Americans (one in three adults), experience chronic pain [Institute of Medicine of the National Academies, 2011] and have a legitimate need for treatment. Individuals with pain and other conditions that controlled substances are approved to treat must have continued access to vital medications, while at the same time, the potential for diversion (i.e. the illegal redirection of prescription medications away from the legal channels of distribution), misuse (i.e. the use of a medication for a medical purpose
Ther Adv Drug Saf 2015, Vol. 6(2) 67-79 DOI: $10.1177 /$ 2042098615569726

(c) The Author(s), 2015. Reprints and permissions: http://www.sagepub.co.uk/ journalsPermissions.nav
Correspondence to: Kyle Simon, Msc. Director of Policy and Advocacy. Center for Lawful Access and Abuse Deterrence, 1000 Potomac Street NW, Suite 150-A Washington, DC 20007 USA

Stacey L. Worthy, Esq. Michael C. Barnes, Esq. Benjamin Tarbell, Esq. DCBA Law \& Policy, 1000 Potomac St., NW, Suite 150-A, Washington, DC 20007, USA 
other than as directed or indicated, whether willful or unintentional, and whether harm results or not), and abuse (i.e. the intentional self-administration of a medication for nonmedical purposes, such as "getting high") must be addressed to stem what the U.S. Centers for Disease Control and Prevention (CDC) has officially identified as a national prescription drug abuse epidemic [CDC, 2014a; Barnes et al. 2010].

A promising approach to advance these goals is through abuse-deterrent formulations (ADFs). $\mathrm{ADF}$ are reformulations of medications with the intent to reduce the attractiveness or drug-liking qualities of a controlled substance by hindering the extraction of active ingredients, limiting their bioavailability, preventing administration through alternative routes, or making abuse of the manipulated product less attractive or rewarding [Greene, 2010]. These medications allow for treatment of medical conditions while reducing the likelihood of diversion, misuse, and abuse, and related adverse outcomes [Turk et al. 2012].

In response to the nation's fastest growing drug problem [ONDCP, 2011], the White House Executive Office of the President and several federal agencies have encouraged the pharmaceutical industry to develop ADFs [ONDCP, 2013]. Although pharmaceutical manufacturers have taken steps to create ADFs, regulatory uncertainty has slowed adoption in the market. Greater regulatory clarity and incentives are critical to expediting the development and use of ADFs for controlled substances commonly subject to abuse.

The first part of this review article provides an overview of the prescription drug abuse epidemic, defines ADF terminology and analyzes the benefits and drawbacks of ADF development and $\mathrm{ADF}$ introduction to the marketplace. We then assess the current state of $\mathrm{ADF}$ adoption in the market in light of industry and government actions. We conclude this article with recommendations for policy makers.

\section{Overview of the evolving prescription drug abuse epidemic}

When taken as prescribed by a licensed physician, controlled substances can effectively treat many conditions [NIH Medline Plus, 2011]. However, over the past decade, the U.S. has seen a drastic increase in controlled substance diversion, misuse, and abuse.
Biology of brain reward and alternative routes of administration

Most drugs of abuse directly or indirectly target the brain's reward system by flooding the circuit with dopamine, a neurotransmitter that regulates movement, emotion, motivation, and feelings of pleasure [NIDA, 2014]. When the system is overstimulated with certain controlled substances, it produces euphoric effects, which strongly reinforce the behavior of substance use, thereby teaching the user to repeat the action. Although the leading route of administration is oral [NIDA, 2014], some individuals alter the route of administration to intensify the effect or as they build a tolerance to the substance [Young et al. 2010]. Alternative routes of administration, including intranasal (e.g. crushing and snorting) and intravenous (e.g. dissolving and injecting) methods, often provide faster drug delivery and onset, and intensified effects [Surratt et al. 2011]. Individuals who use altered routes of administration are at an increased risk for overdose and the development or exacerbation of substance use disorders [Surratt et al. 2011; McCabe et al. 2007]. ADFs prevent inexperienced substance users from successfully ingesting substances via altered routes of administration, and thereby prevent associated overdoses and escalation of substance use, resulting in significant personal and public health benefits.

\section{Availability and abuse of prescription drugs}

Many Americans mistakenly believe that prescription drugs are less dangerous when abused than illicit drugs because they are approved by the U.S. Food and Drug Administration (FDA) [ONDCP, 2011]. Many well-meaning individuals are unaware of the risk associated with sharing their prescription medications with a friend or family member, and although parents often remember to lock the liquor cabinet, many do not think to lock the medicine cabinet, leaving unused medication accessible to teens [ONDCP, 2011]. Between 2011 and 2012, more than 54\% of individuals aged 12 or older who abused prescription drugs reported that they received the medications from a friend or relative with a prescription [SAMHSA, 2013a]. Among those individuals who obtained the drugs from a friend or relative, $82.2 \%$ of the friends and relatives obtained the drugs from just one physician [SAMHSA, 2013a].

This increase in abuse of controlled substances and resulting overdose deaths is correlated with 
significant increases in the supply of such medications, including opioids, central nervous system depressants (e.g. barbiturates and benzodiazepines), and stimulants (e.g. amphetamines and methylphenidate), among others, over the past two decades [CDC, 2012]. For instance, the CDC has reported a $300 \%$ increase in prescription sales of opioids since 1999 [CDC, 2013]. Moreover, alprazolam, a benzodiazepine, was the mostly commonly prescribed psychiatric medication in 2011 [SAMHSA, 2014a]. The prescribing of stimulants has increased steadily over the past two decades as well; $4.3 \%$ of all children aged 4-17 today receive a prescription for a stimulant to treat attention deficient/hyperactive disorder (ADHD) [Connor, 2011].

The increased use of controlled substances has led to greater availability within communities and increased abuse of such medications in the U.S. [Schaeffer, 2012]. In 2011, there were over 1.2 million emergency department visits related to prescription drug abuse [SAMHSA, 2014a]. Approximately 600,000 of those visits involved opioid abuse [SAMHSA, 2013b], and in 2011, opioids were involved in 16,651 deaths - exceeding deaths involving any other drug or drug class, licit or illicit, with the exception of alcohol [CDC, 2014b, 2014c; Jones et al. 2010]. Many of the individuals who died of drug overdoses had a combination of benzodiazepines and opioids or alcohol and opioids in their systems [CDC, $2014 \mathrm{c}, 2014 \mathrm{~d}]$. The number of emergency room visits between 2005 and 2010 involving abuse of alprazolam more than doubled from 57,419 to 124,902 visits [SAMHSA, 2013b], involving stimulant abuse tripled from 5,212 to 15,585 [SAMHSA, 2013a], and involving the overmedication (i.e. taking more than the prescribed dose) of zolpidem (i.e. the active ingredient in prescription sleep aids) doubled from 14,730 visits to 31,994 [SAMHSA, 2013b]. [SAMHSA, 2013c, 2014a, 2014b].

\section{Transition from prescription opioids to buprenorphine and heroin}

The prescription drug abuse epidemic is evolving. As a result of recent successes in reducing the supply of opioids available for abuse, data suggest that many people who abuse substances have switched from prescription drugs to illicit drugs, particularly heroin, which acts on the same receptors in the brain as opioids, thereby producing a similar feeling of euphoria [Dasgupta, 2014; Kuehn et al.
2014; Herald Tribune, 2014; Unick et al. 2013]. This progression may have occurred because heroin is cheaper and easier to obtain in some locations [Muhuri et al. 2013]. In 2012, the FDA approved an extended-release oxycodone with abuse-deterrent properties that make it harder to "crush the medicine into powder, limiting the ability to snort, inject or smoke it" [Emery, 2012]. The reformulated medication's introduction into the market appears to be correlated with the shift from abusing the non-abuse-deterrent extended release (ER) oxycodone to both buprenorphine (a medication that treats opioid addiction by limiting cravings and withdrawal symptoms) and heroin because of comparative availability and affordability [Krantz, 2014; Green, 2013; Dart, 2012; Perez et al. 2014; Goodnough, 2011].

According to government data, the number of past-year heroin users nearly doubled between $2007(373,000)$ and $2012(669,000)$, and approximately 156,000 individuals identified as firsttime users in 2012 compared with 90,000 first-time users reported in 2006 [SAMHSA, 2013a]. However, it should be noted that the rise in heroin abuse began before the introduction of reformulated opioids, suggesting that other factors aside from the transition to ADFs contributed to the rise.

\section{Benzodiazepines and stimulants}

Abuse of stimulants and benzodiazepines, which produce sedation, muscle relaxation, and lower anxiety levels, has also increased [Thompson, 2013]. Prescription stimulants used to treat ADHD have become drugs of choice for young adults, with as many as $20 \%$ of college students using such drugs for nonmedical purposes, as well as for many professional athletes [Corra, 2010; Doyel, 2014].In 2010 alone, 1.1 million Americans reported abusing stimulants [NIDA, 2011a].

Intranasal and intravenous abuse of such medications results in an instant and intensely gratifying euphoria similar to cocaine [NIDA, 2011a]. Prescription stimulants have the potential for dependence and addiction, and may result in psychosis, seizures, and cardiovascular complications [NIDA, 2011a, 2011b]. The rate of emergency department visits involving central nervous system stimulants increased $292 \%$ between 2004 and 2011 [SAMHSA, 2013d]. Unfortunately, at this time, there is only one stimulant with FDAapproved abuse-deterrent labeling on the U.S. 
market. (The FDA-approved label for Vyvanse, lisdexamphetamin dimesylate, a prodrug of dexamphetamine, describes a reduction in "drug liking." However, the label is not structured and worded according to the current FDA draft guidance on abuse-deterrent formulations because the product was approved prior to the publication of the guidance [FDA, 2014a].) The FDA has confirmed the need for abuse-deterrent formulations of stimulants in order to address intranasal and intravenous abuse [FDA, 2014b]; however, to date, the FDA has not provided guidance on ADFs for any controlled substance other than opioids.

Benzodiazepines are also commonly abused in the U.S. and are particularly dangerous when taken in combination with alcohol or other medications [Center for Substance Abuse Research, 2013]. Although the most common route of administration differs depending on the particular drug, benzodiazepines are often abused via oral (e.g. swallowed whole, crushed and swallowed, or smoked), intranasal, and intravenous ingestion; however, nonoral use of benzodiazepines is limited [Center for Substance Abuse Research, 2013; Evans and Sullivan, 2014]. In 2011, benzodiazepines were involved in $30.6 \%$ of prescription drug-related overdose deaths [CDC, 2014c]. There are currently no benzodiazepines with FDAapproved abuse-deterrent labeling on the market.

\section{Unintended consequence of abuse: significant restrictions in patient access}

An average of 45 Americans died every day in 2010 of opioid-related overdoses [ONDCP, 2014]. This alarming statistic galvanized policymakers and stakeholders to enact policies and raise awareness, but it has also resulted in the reduction of legitimate access to prescription drugs for some patients [Foreman, 2013].

New prescribing restrictions and increased enforcement of controlled substance laws and regulations have had a chilling effect on prescribing and dispensing [Anson, 2014]. Some physicians have become reluctant to write prescriptions for opioids out of fear of facing criminal or civil liability for patient overdoses [Anson, 2014]. In certain areas of the country, patients with chronic pain are unable to find physicians to treat them [Berens and Armstrong, 2014].

Pharmacists are increasingly refusing to fill legitimate prescriptions for controlled substances for individuals with pain [Anson, 2014]. The American Medical Association and the American Academy of Pain Management reported receiving a flood of complaints from patients and physicians regarding pharmacies refusing to fill prescriptions for opioid pain medications [Anson, 2014]. Various pharmacy chains have adopted policies that allow pharmacists to refuse to dispense pain medications if they believe that the prescription is for an illegitimate medical purpose, resulting in patient profiling [DOJ, 2005; Lasich, 2013]. They base their policies on a federal regulation that states that pharmacists are required to ensure that prescriptions for controlled substances are issued for a legitimate medical purpose [DOJ, 2005; Lasich, 2013]. These policies are applied inconsistently and place patient safety at risk by delaying or preventing dispensation of medication while pharmacies gather information above and beyond requirements set forth by state and federal regulations [Anson, 2014; PainDr.com, 2013].

\section{Terminology and overview of types of ADFs}

Controlled substances are abused in a number of methods, including oral, intranasal, and intravenous ingestion, among other means. ADFs limit one or more forms of such abuse by reducing the attractiveness or drug-liking qualities of a controlled substance by:

(1) Hindering the extraction of active ingredients.

(2) Decreasing their bioavailability through product manipulation, thereby reducing the feeling of euphoria.

(3) Preventing administration through alternative routes.

(4) Making abuse of the manipulated product less attractive or rewarding [Greene, 2010; Schaeffer, 2012].

Currently approved ADFs offer advantages while posing a common limitation; that is, they do not deter abuse involving multiple drug doses by oral administration.

ADFs include, but are not limited to, products with one or more of the following types of abusedeterrent technology:

(1) Physical barriers: to prevent chewing, crushing, cutting, grating or grinding. 
(2) Chemical barriers: to resist extraction of the opioid using common solvents, such as water, alcohol, or other organic solvents.

(3) Agonist/antagonist combinations: to interfere with, reduce, or defeat the euphoria associated with abuse upon manipulation of the product by acting on the mu, kappa, and delta opioid receptors.

(4) Aversion: to combine substances in order to produce an unpleasant effect if the dosage form is manipulated prior to ingestion or a higher dosage than directed is used.

(5) Delivery systems: certain drug release designs or methods of drug delivery that offer resistance to abuse, such as depot injectable formulations or implants.

(6) Prodrugs: to lack activity until transformed in the gastrointestinal tract, thereby making intravenous injection or intranasal abuse less attractive.

(7) Combination: products that combine two or more of the above-mentioned methods [FDA, 2013a].

For instance, Researchers are developing innovative ADFs that are expected to reduce the qualities that make certain controlled substances desirable for abuse [Cara, 2014].

For a new drug to obtain an "abuse-deterrent" label from the FDA, the agency specifically requires that the new product be studied for abuse potential relative to a previously approved version of the product as the positive control, through premarketing studies (i.e. laboratory manipulation and extraction, pharmacokinetic, and clinical abuse potential studies) and postmarketing studies [FDA, 2013a]. The FDA has noted that in most cases, data from all three of these categories of studies are required in order to obtain a full and scientifically rigorous understanding of the impact of a technology on a product's abuse potential [FDA, 2013a].

\section{Benefits of ADFs}

Abuse-deterrent medications protect the community against prescription drug abuse by deterring or reducing certain forms of abuse. For example, in April 2013, the FDA approved abuse-deterrent labeling for a reformulated ER oxycodone product, indicating "that the product has physical and chemical properties that are expected to make abuse via injection difficult and to reduce abuse via the intranasal route (snorting)" [FDA, 2013b].
The FDA granted such labeling because well controlled clinical studies demonstrated significant reduction, up to $60 \%$, in various abuse-related parameters and indicators following the reformulated medication's introduction into the market in April 2010 [Severtson et al. 2010]. In the two years post reformulation, the American Association of Poison Control Centers National Poison Data System reported that oxycodonerelated "intentional events (e.g., abuse and suspected suicide) and unintentional events (e.g., misuse and therapeutic errors) each declined by $25 \%$. . . [while] reports for each of these events increased for other single-entity oxycodone products" [Coplan et al. 2013, pp. 1277.].

ADFs simultaneously preserve patient access to medications and can limit abuse and its consequences [Turk et al. 2012; Katz, 2008]. Currently available ADFs can reduce the likelihood of the following:

(1) Patients progressing to abuse via nonoral administration routes.

(2) Individuals with established substance use disorders developing new complications related to their disorder.

(3) Misuse due to the unknown risks associated with product manipulation, which can result in overdose-related morbidity and mortality [Turk et al. 2012].

Even an incremental reduction in abuse can have a significant impact on the community by reducing the costly social, physical, mental, and public health problems resulting from substance abuse [HealthyPeople.gov, 2014]. Substance abuse has been shown to result in teenage pregnancy, the spread of infectious diseases, domestic violence, child abuse, motor vehicle crashes, physical fights, crime, homicide, and suicide [HealthPeople.gov, 2014]. By preventing abuse and diversion, the likelihood of these substance-abuse-related consequences developing may also be reduced.

Additionally, by reducing the likelihood of abuse, ADFs reduce the likelihood of civil and criminal liability that physicians and pharmacists face as a result of overdose-related deaths caused by patient abuse. Physicians may be more willing to prescribe and pharmacies may be more willing to dispense abuse-deterrent controlled substances to patients with legitimate needs, thereby reducing barriers to access for patients with legitimate needs. 


\section{Counterarguments against ADF adoption and responses}

\section{Cost}

Some critics argue that the monetary cost of ADFs outweigh the formulations' benefits. According to this argument, new ADFs are formulations of "branded products," which are more expensive than generic, non-abuse-deterrent formulations of the same medication. If the FDA were to remove from the market the less expensive generics that lack abuse-deterrent features, consumers would be forced to pay for the more costly medications, potentially impeding their access to pain medications [Twillman, 2014]. Some individuals who cannot afford prescription opioids may look for less expensive substances from the black market to relieve their pain or reduce the symptoms of withdrawal, thereby increasing the likelihood of harm [Turk et al. 2012].

This argument is muted once ADFs become widely available, and when manufacturers begin producing generic products with $\mathrm{ADF}$, market prices will adapt. To that end, the Generic Pharmaceutical Association (GPhA) has stated that it "recognize[s] the importance of balancing patient access to medicine with efforts to minimize abuse" and that it is committed to making contributions in the field of abuse deterrence [GPhA, 2013]. When third-party payers include ADFs in covered formularies, consumers will not have to pay out of pocket the entire cost for the medication [Twillman, 2014]. Improving public health and safety by transitioning to ADFs and removing their traditional counterparts will reduce the supply of commonly abused medications. Additionally, many states and pharmaceutical manufacturers have patient assistance programs to help qualifying patients obtain free or low-cost medications [Partnership for Prescription Assistance, 2014].

Individuals who adhere to their physiciandesigned treatment plan do not tamper with medications, and store and dispose of medications properly have argued that they would bear the financial burden of purchasing an $\mathrm{ADF}$ without garnering any greater personal benefit from the increased expense [Turk et al. 2012; Twillman, 2014]. This argument fails to acknowledge that prescription drug abuse is a societal problem. The majority of individuals who abuse prescription drugs receive those medications from a friend or relative with a prescription [SAMHSA, 2013a]. Diversion occurs in the best of circumstances, placing responsibility in the hands of every individual with a controlled substance prescription to prevent their own friends and relatives from abuse.

Reducing the risk of substance use also carries significant cost-savings benefit for all Americans. Illicit drug use costs the country an estimated $\$ 193$ billion a year when factoring in public health, crime, and lost productivity [ONDCP, 2012]. A recent study found that prescription drug abuse resulted in annual costs of approximately $\$ 3.6$ billion in Montana alone [Davis and Polzin, 2011]. Private and public health care payers spend approximately $\$ 72.5$ billion per year on the medical and prescription costs associated with opioid addiction and diversion [Katz et al. 2013]. Strategies to prevent drug abuse can significantly reduce societal costs as well as individual costs (e.g. the cost of suffering and emergency care) resulting from addiction and overdoses [Rossiter et al. 2014]. Reformulated oxycodone was associated with annual medical cost savings of approximately $\$ 430$ million in the U.S. [Rossiter et al. 2014]. A budget impact model to quantify the potential cost savings associated with a hypothetical $\mathrm{ADF}$ designed to deter common forms of abuse was projected to save third party payers up to $\$ 1.6$ billion per year [Katz et al. 2013].

\section{Shifting supply}

Critics argue that while increased use of ADFs may decrease abuse of particular medications, individuals who want to abuse medications will simply seek another product they can abuse [Schaeffer, 2012]. Simultaneously with transitioning the market to $\mathrm{ADFs}$, policy makers must improve and expand demand-reduction initiatives, including ensuring that individuals with substance use disorders are identified early in the progression of their disorders and steered into treatment for substance use [Budman et al. 2009]. Moreover, $\mathrm{ADF}$ will have a larger impact on reducing abuse after other non-ADFs are no longer available [Schaeffer, 2012]. Supply-reduction policies can only be successful when counter-balanced with effective demand-reduction efforts.

\section{Limitations}

Others argue that ADFs are still in their nascent stages, the technology has too many limitations to adopt, formulations may not prevent all forms of abuse, and individuals can still take too many pills 
orally and overdose [Center for Lawful Access and Abuse Deterrence (CLAAD), 2013]. For example, the FDA noted that data for reformulated oxycodone, which received FDA-approved ADF labeling, are not yet sufficiently mature to confirm expectations that the medication makes abuse via injection difficult or reduces abuse via the intranasal route. The FDA also noted that the reformulated oxycodone is not intended or believed to have any impact on "the most common form of abuse of . . . prescription opioids swallowing intact tablets or capsules" [CLAAD, 2013].

Despite current technological limitations, any reduction in prescription drug abuse and the related risks of overdoses, diseases contracted by intravenous drug use (e.g. hepatitis, human immunodeficiency virus, etc.), or deaths is a positive societal outcome [Turk et al. 2012]. ADFs that employ mechanisms to prevent crushing, dissolving, melting, and so on may positively impact the health and functioning of individuals who prefer those alternate routes of administration for that particular drug [Budman et al. 2009].

$\mathrm{ADF}$ must be in the market in order to determine effectiveness and make improvements where needed. The current practice of limited and incremental regulatory adoption limits the willingness of manufacturers to fund research for comprehensive $\mathrm{ADF}$ development. With broader regulatory support and as new ADFs increase market share, manufacturers will have the economic incentives needed to research and develop next-generation abuse-deterrent technologies. The next generation of investments will include efforts to reduce additional forms of abuse, including excessive oral ingestion of intact tablets or capsules.

\section{Not all controlled substances are abused}

A final argument against ADFs is that not all controlled substances are abused and, therefore, not all necessitate an abuse-deterrent formulation [CLAAD, 2013]. While the FDA has stated that it is not feasible or in the public interest to require all opioid products to be abuse deterrent [CLAAD, 2013], as noted above, other classes of medications are abused in the U.S. via nonoral routes, and so ADFs should not be limited only to opioids.

Pursuant to the Controlled Substances Act, a controlled substance's potential for abuse is reflected in its federal scheduling. Schedule I substances have a high potential for abuse, have no currently accepted medical use, and are not approved for safe use under medical supervision [DOJ, 1980]. Schedule II substances have a high potential for abuse; have current accepted medical use, which may be severely restricted; and may lead to severe psychological or physical dependence if abused [DOJ, 1980]. Schedule III substances have the potential for abuse less than Schedule I and II substances, have currently accepted medical uses, and may lead to moderate or low physical dependence or high psychological dependence if abused [DOJ, 1980]. Schedule IV substances have low potential for abuse relative to substances in Schedule III, have currently accepted medical use, and may lead to limited physical dependence or psychological dependence relative to Schedule III substances if abused [DOJ, 1980]. Schedule V substances have low potential for abuse relative to substances in Schedule IV, have a currently accepted medical use in treatment, and may lead to limited physical dependence or psychological dependence relative to the substances in Schedule IV [DOJ, 1980].

An appropriate incremental approach to transitioning the market to $\mathrm{ADFs}$ would be to require all Schedule II controlled substances to incorporate abuse-deterrent technology by a date certain while granting the FDA the authority to require ADFs for other non-Schedule II controlled substances that are commonly abused via nonoral routes, such as alprazolam, phenobarbital, and zolpidem. The timeline for a mandatory market shift to controlled substances should be adequately tight to reflect the urgency of the prescription drug abuse epidemic. A short time frame, supported by a regulatory pathway, will give manufacturers the incentive currently lacking to make needed investments to develop abusedeterrent alternatives.

\section{ADF adoption in the pharmaceutical market}

\section{Current status}

As of December 2014, there are four ER/long-acting (LA) opioid analgesics with FDA-approved ADF labeling [FDA, 2014c]. Reformulated oxycodone ER, hydrocodone bitartrate, and morphine sulfate naltrexone hydrochloride have physical and chemical properties that are expected to make abuse difficult, while oxycodone hydrochloride/ naloxone hydrochloride ER is an agonist/antagonist 
(morphine sulfate naltrexone hydrochloride received implied ADF labeling in August 2009, and stronger, more explicit FDA-approved ADF labeling in October 2014) [Drug Topics, 2013; FDA, 2014c].

Upon granting abuse-deterrent labeling for the ER/LA oxycodone ER product, the FDA determined, based on the associated risks of abuse, that the "benefits of [the original oxycodone] no longer outweigh its risks and that original [oxycodone] was withdrawn from sale for reasons of safety or effectiveness" [Pizzi, 2013]. Thus, the FDA announced that it would not consider for approval any generics based on the original oxycodone formulation [Pizzi, 2013].

Additionally, the manufacturer of an oxymorphone ER product obtained FDA approval of a reformulation of its drug in 2011 [Pizzi, 2013; Endo Pharmaceuticals, Inc., 2012]. Yet, in 2013, the FDA declined to approve ADF labeling for the new oxymorphone ER product [Federal Register, 2013]. The FDA determined that, although the reformulation "better resisted attempts to crush it" than the original product, the reformulated drug could be "compromised when subjected to other forms of manipulation" and could be "prepared for snorting using commonly available tools and methods" [Pizzi, 2013]. Accordingly, the FDA decided to continue to consider for approval generic, nonabuse-deterrent formulations of the original product [Pizzi, 2013]. Nevertheless, the manufacturer of oxymorphone ER is working with the FDA to substantiate the ADF labeling request by conducting an intranasal human abuse liability trial and gathering additional postmarketing surveillance and epidemiological data [Morningstar, 2013]. In the meantime, data indicate that the reformulated oxymorphone ER has resulted in a decline of abuse [Dart, 2014]. Specifically, abuse through the intranasal route has dropped significantly, which is consistent with the incremental improvement of the reformulation into a crush-resistant form [Cassidy et al. 2014]. Moreover, as part of the public dialogue leading up to the FDA's denial of the abuse-deterrent labeling for the oxymorphone ER product, Commissioner Margaret Hamburg stated that the FDA has "the authority to refrain from approving non-abuse deterrent formulations of [a] drug and to initiate procedures to withdraw non-abuse deterrent versions already on the market" [FDA, 2013c].

\section{FDA's position on abuse-deterrent technology}

While the FDA has stated that it strongly encourages and has the authority to foster the development of ADFs, it has stated that it does not approve of an ADF class-wide requirement for opioids and stimulants [FDA, 2014b; CLAAD, 2013]. The FDA has repeatedly stated that the science of abuse-deterrent technology is in its early stages: "Both the drug and formulation technologies involved and the clinical, epidemiological, and statistical methods for evaluating those technologies are still rapidly evolving" [CLAAD, 2013]. Accordingly, the FDA posited that a mandatory transition to abuse-deterrent opioids is not "feasible or in the interest of public health at this time" [CLAAD, 2013]. The FDA declared that it will use a "product-by-product approach" to decisions about the safety and effectiveness of opioid products and "continue to evaluate [its] approach to regulatory decisions concerning these products" [CLAAD, 2013].

As of December 2014, the FDA has not released guidance for generic $\mathrm{ADF}$ products, leading to delays in generic adoption of ADFs [FDA, 2014a]. According to a generics industry working group established by the FDA, without guidance, the generic industry is uncertain as to which criteria must be proved to establish that a generic product that has adopted abuse-deterrent features is not inferior to its reference-listed branded ADF [FDA, 2014a]. Therefore, the working group has called for meaningful testing and acceptance criteria [FDA, 2014a].

The FDA's current approach slows innovation by sending a signal to manufacturers that there is no pressing need to develop abuse-deterrent formulations of controlled substances. It compromises incentives for manufacturers to spend the time and money required to develop $\mathrm{ADF}$ s by conceding no market benefit over existing, non-abusedeterrent products as in the case of oxymorphone ER. This regulatory environment, as currently constructed, has the unintended consequence of discouraging investment in new technology.

\section{Recommendations}

Waiting for the "perfect" technology before a grand transition to abuse-deterrent medications leads to inaction. Today's policy preserves the status quo of substance abuse, overdoses, and deaths, and it stifles investments in new innovation as manufacturers have no clear incentive to allocate the time and money needed for new technology. 
Abuse-deterrent medications have the potential to reduce the public health burden of prescription opioid abuse. They require both technically successful formulations and appropriate scientific assessment, widespread market penetration, and rational expectations of their benefits [Pittman, 2012]. When promising evidence for an abusedeterrent approach exists, but not enough data have been gathered to draw conclusions about the particular approach, the FDA should dedicate its resources on an expedited basis to work with manufacturers to help collect and report the data necessary to support a conclusion, if possible, that an abuse-deterrent product has a lower abuse potential by certain routes of administration than a prior formulation.

Congress should require the FDA to enforce its stated authority consistently so that when a medication is granted abuse-deterrent labeling, the FDA will refrain from approving non-abuse-deterrent formulations and initiate procedures to withdraw non-abuse-deterrent versions already on the market unless there unique patient needs or public health reasons not to do so. Any new generic drug referencing a branded ADF in its application for FDA approval must demonstrate that the generic drug does not have inferior abuse-deterrent properties than the branded ADF drug. Similarly, if a branded drug becomes a drug with an ADF, then any FDA-approved generic drug that references the branded drug's prior, non-ADF should no longer be considered bioequivalent to, or to have the same therapeutic effects as, the reformulated ADF drug unless and until the generic drug demonstrates that it does not have abuse-deterrent properties inferior to the branded ADF drug.

Congress should also require manufacturers of all Schedule II controlled substances (and other controlled substances at the discretion of the FDA) without abuse-deterrent technologies to convert their products to ADFs by a specific date. Manufacturers should be given a deadline by which to replace non-abuse-deterrent products with alternatives. The legislation should require federally funded prescription drug benefit plans to cover ADFs to ensure their accessibility to consumers. To do otherwise would undermine the eventual widespread adoption of ADFs.

In order for manufacturers to meet these requirements with a clear understanding of what is expected of them, the FDA must finalize guidance for pharmaceutical manufacturers on ADF development and labeling for branded and generic opioids and all Schedule II controlled substances.

\section{Conclusion}

Prescription drug abuse results in overdoses and deaths every day in the U.S. Abuse-deterrent medications have the potential to reduce the risk of misuse and abuse while ensuring access to treatment for those who legitimately need such medications. Federal ADF policy does not reflect the urgency of the prescription drug abuse epidemic and does not go far enough toward changing the status quo. Policies must be implemented to encourage innovation and a market shift toward $\mathrm{ADF}$ by ensuring any generic medication that references a branded ADF demonstrates that it does not have abusedeterrent properties inferior to the branded ADF product. The policy must also require federal prescription drug benefit plans to cover $\mathrm{ADF}$ s to ensure consumers have access to such medications. By doing this, the risk of prescription drug abuse may be reduced while ensuring access to medications for those who legitimately need them.

\section{Conflict of interest statement}

CLAAD receives funding from businesses in the health care industry that share CLAAD's mission to reduce prescription drug fraud, diversion, misuse, and abuse while advancing consumer access to high-quality health care. CLAAD's funders include pharmaceutical companies, treatment centers, and laboratories, and are disclosed online at claad.org

\section{Funding}

This manuscript is funded by the Center for Lawful Access and Abuse Deterrence (CLAAD).

\section{References \\ Anson, P. (2014) DEA: doctors and pharmacies responsible for pain med denials. Available at: http://americannewsreport.com/nationalpainreport/ dea-doctors-pharmacies-responsible-pain-med- denials-8822886.html (accessed 6 January 2015).}

Barnes, M., Barthwell, A., Marson, J. and Paillard, F. (2010) National prescription drug abuse prevention strategy. Available at: http://claad.org/wp-content/ uploads/2013/10/2010_National_Strategy.pdf (accessed 6 January 2015).

Berens, M. and Armstrong, K. (2014) New state law leaves patients in pain. Available at: http://seattletimes. com/html/localnews/2016994769_silent12.html

(accessed 6 January 2015). 
Budman, S., Grimes Serrano, J. and Butler, S. (2009) Can abuse deterrent formulations make a difference? Expectation and speculation. Harm Reduct f 6: 8.

Cara Therapeutics (2014) Cara Therapeutics announces positive results from human abuse liability trial of peripheral opioid for acute pain, I.V. CR845. Available at: http://ir.caratherapeutics.com/ releasedetail.cfm?releaseid $=878862$ (accessed 27 January 2015).

Cassidy, T., Beaumont, J., Urdaneta, V., Budman, S. and Butler, S. (2014) The changing abuse ecology: implications for evaluating the abuse patterns of extended-release oxymorphone and abuse-deterrent opioid formulations. Available at: http://conference. painweek.org/media/mediafile_attachments/04/724painweek2014acceptedabstracts.pdf (accessed 6 January 2015).

CDC (2012) CDC grand rounds: prescription drug overdoses - a U.S. epidemic. Available at: http://www. cdc.gov/mmwr/preview/mmwrhtml/mm6101a3.htm (accessed 6 January 2015).

CDC (2013) Policy impact: prescription painkiller overdoses. Available at: http://www.cdc.gov/ homeandrecreationalsafety/rxbrief/ (accessed 6 January 2015).

CDC (2014a) Opioid painkiller prescribing. Available at: http:/www.cdc.gov/vitalsigns/pdf/2014-07vitalsigns.pdf (accessed 6 January 2015).

CDC (2014b) Fact sheets - alcohol use and your health. Available at: http://www.cdc.gov/alcohol/factsheets/alcohol-use.htm (accessed 6 January 2015).

CDC (2014c) Prescription drug overdose in the United States: fact sheet. Available at: http://www.cdc. gov/homeandrecreationalsafety/overdose/facts.html (accessed 6 January 2015).

CDC (2014a) Alcohol involvement in opioid pain reliever and benzodiazepine drug abuse-related emergency department visits and drug-related deaths. Available at: http://www.cdc.gov/mmwr/preview/ $\mathrm{mmwrhtml} / \mathrm{mm} 6340 \mathrm{a} 1 . \mathrm{htm}$ ?s_cid=mm6340a 1 (accessed 6 January 2015).

Center for Substance Abuse Research (2013) Benzodiazepines. Available at: http://www.cesar.umd. edu/cesar/drugs/benzos.asp (accessed 6 January 2015).

CLAAD (2013) Letter from Janet Woodcock. Available at: http://claad.org/wp-content/ uploads/2013/10/FDA-Response-to-CLAAD-CitizenPetition-131025.pdf (accessed 6 January 2015).

Connor, D. (2011) Problems of overdiagnosis and overprescribing in ADHD. Available at: http://www. psychiatrictimes.com/adhd/problems-overdiagnosisand-overprescribing-adhd (accessed 6 January 2015).
Coplan, P., Kale, H., Sandstrom, L., Landau, C. and Chilcoat, H. (2013) Changes in oxycodone and heroin exposures in the national poison data system after introduction of extended-release Oxycodone with abuse-deterrent characteristics. Pharmacoepidemiol Drug Saf 22: 1274-1282.

Corra, C. (2010) Abusing prescription Adderall hurts those with ADHD. Available at: http://www. thedaonline.com/article_5a527a21-9605-5538-86b8654b3c047a29.html (accessed 6 January 2015).

Dart, R. (2012) Trends of opioid misuse and diversion: lessons from the United States. Available at: http://www.mountsinai.on.ca/care/pain_management/ lecture-series/Canada_Dart_for\%20distribution $\% 20$ (1).pdf (accessed 6 January 2015).

Dart, R. (2014) Should all opioid medications have abuse deterrent technology? Available at: http://www. radars.org/Portals/1/AnnualMeeting/2014/Annual\%20 Meeting\%202014\%20Presentations/Dart_Should\%20 All $\% 20$ Opioids $\% 20 \mathrm{Be} \% 20$ Required $\% 20$ to $\% 20$ Use\%20ADF.pdf (accessed 6 January 2015).

Dasgupta, N. (2014) RADARS system, Subutex \& Suboxone: how much is prescribed vs. abuse/diversion reports. Available at: http://buprenorphine.samhsa. gov/presentations/Dasgupta.pdf (accessed 6 January 2015).

Davis, G. and Polzin, P. (2011) The economic cost of prescription drug abuse in Montana. Available at: http://mbcc.mt.gov/PlanProj/Projects/PDMP/ Prescription\%20Drug\%20Abuse\%2020110629.pdf (accessed 6 January 2015).

DOJ (1980) 21 U.S.C. § 812. Available at: http:// www.deadiversion.usdoj.gov/21 cfr/21 usc/812.htm (accessed 6 January 2015).

DOJ (2005) 21 C.F.R. $§ 1306.04$. Available at: http:// www.deadiversion.usdoj.gov/21 cfr/cfr/1306/1306_04. htm (accessed 6 January 2015).

Doyel, G. (2014) Adderall the new drug of choice for many major-leaguers. Available at: http://www. cbssports.com/general/writer/gregg-doyel/24706564/ adderall-the-new-drug-of-choice-for-many-majorleaguers (accessed 6 January 2015).

Drug Topics (2013) FDA nixes generic OxyContin, approves abuse-deterrent labeling for reformulated OxyContin. Available at: http://drugtopics. modernmedicine.com/drug-topics/news/drug-topics/ hse-professional-practice/fda-nixes-generic-oxycontinapproves-abuse-de?page $=$ full (accessed 6 January 2015).

Emery, G. (2012) OxyContin abuse down with time-release formula. Available at: http://articles. chicagotribune.com/2012-07-11/lifestyle/sns-rtus-usa-health-painkillersbre86a 1 aw-20120711_1_ oxycontin-abuse-new-formulation-purdue-pharma (accessed 6 January 2015). 
Endo Pharmaceuticals, Inc. (2012) Citizen petition. Available at: http://www.regulations. gov/\#!documentDetail;D=FDA-2012-P-0895-0001 (accessed 6 January 2015).

Evans, E. and Sullivan, M. (2014) Abuse and misuse of antidepressants. Subst Abuse Rehabil 5: 107-120.

FDA (2013a) Guidance for industry: abusedeterrent opioids - evaluation and labeling. Available at: http://www.fda.gov/downloads/Drugs/ GuidanceComplianceRegulatoryInformation/ Guidances/UCM334743.pdf (accessed 6 January 2015).

FDA (2013b) FDA approves abuse-deterrent labeling for reformulated OxyContin. Available at: http://www. fda.gov/newsevents/newsroom/pressannouncements/ ucm348252.htm (accessed 6 January 2015).

FDA (2013c) FDA approves new extended-release oxycodone with abuse-deterrent properties. Available at: http://www.fda.gov/NewsEvents/Newsroom/ PressAnnouncements/ucm406407.htm (accessed 6 January 2015).

FDA (2013d) Remarks by Margaret A. Hamburg: 2013 national Rx drug abuse summit. Available at: http://www.fda.gov/NewsEvents/Speeches/ ucm346315.htm (accessed 6 January 2015).

FDA (2014a) Vyvanse ${ }^{\mathrm{TM}}$ (lisdexamfetamine dimesylate). Available at: http://www.accessdata. fda.gov/drugsatfda_docs/label/2007/021977lbl.pdf (accessed 6 January 2015).

FDA (2014b) Petition denial response letter to John C. Kulli MD redacted. Available at: http:// www.regulations.gov/\#!documentDetail;D=FDA2006-P-0453-0005 (accessed 6 January 2015).

FDA (2014c) FDA approves extended-release, singleentity hydrocodone product with abusedeterrent properties. Available at: http://www.fda.gov/ NewsEvents/Newsroom/PressAnnouncements/ ucm 423977.htm (accessed 6 January 2015).

FDA (2014d) Development and evaluation of abuse deterrent formulations: a generic industry perspective. Available at: http://www.fda.gov/downloads/Drugs/ NewsEvents/UCM422385.pdf (accessed 6 January 2015).

Federal Register (2013) Determination that OPANA ER (oxymorphone hydrochloride) drug products covered by new drug application 21-610 were not withdrawn from sale for reasons of safety or effectiveness. Available at: http://www.gpo.gov/fdsys/ pkg/FR-2013-06-25/pdf/2013-15099.pdf (accessed 6 January 2015).

Foreman, J. (2013) Fighting abuse but hurting pain patients: FDA seeks new opioid limits. Available at: http://commonhealth.wbur.org/2013/10/fda-opioidcontrol-tightens (accessed 6 January 2015).
Goodnough, A. (2011) Drug is harder to abuse, but users persevere. Available at: http://www.nytimes. com/2011/06/16/health/16oxy.html?_r=2\&emc=eta $1 \&$ (accessed 6 January 2015).

GPhA (2014) Statement from Ralph G. Neas, president and CEO, GPhA on FDA decision on abuse-deterrent formulations of OxyContin. Available at: http://www.gphaonline.org/gpha-media/press/ statement-from-ralph-g-neas-president-and-ceo-gphaon-fda-decision-on-abuse-deterrent-formulations-ofoxycontin (accessed 6 January 2015).

Green, T. (2013) Cumulative impacts of ADFs/TRFs: evidence from ASI-MV \& the RARx study. Available at: http://www.radars.org/Portals/1/03_Green

RADARS_2013_Annual_Meeting.pdf (accessed 6 January 2015).

Greene, L. (2010) Pain management 2010: new and emerging abuse-deterrent technologies. Available at: http://primeinc.org/downloads/38PR092.pdf (accessed 6 January 2015).

HealthPeople.gov (2014) Substance abuse. Available at: https:/www.healthypeople.gov/2020/topics-objectives/ topic/substance-abuse (accessed 6 January 2015).

Herald Tribune (2014) From pill-mill pariah to paragon. Available at: http://www.heraldtribune. com/article/20140708/OPINION/307089999/-1/ HEALTHMATTERS?Title=From-pill-mill-pariahto-paragon (accessed 6 January 2015).

Institute of Medicine of the National Academies (2011) Report from the Committee on Advancing Pain Research, Care and Education, Relieving Pain in America. Available at: http://books.nap.edu/openbook. php?record_id=13172\&page $=1$ (accessed 6 January 2015).

Jones, C., Mack, K. and Paulozzi, L. (2013)

Pharmaceutical overdose deaths, United States, 2010. FAMA 309: 657-659.

Katz, N. (2008) Abuse-deterrent opioid formulations: are they a pipe dream? Curr Rheumatol Rep 10: 11-18.

Katz, N., Birnbaum, H., Brennan, M., Freedman, J., Gilmore, G., Jay, D. et al. (2013) Prescription opioid abuse: challenges and opportunities for payers. $A m \mathcal{F}$ Manag Care 19: 295-302.

Krantz, L. (2014) Special report: state spends millions on addiction-fighting drug that is diverted for street sale. Available at: http://vtdigger.org/2014/02/11/ special-report-state-spends-millions-addiction-fightingdrug-diverted-street-sale/ (accessed 6 January 2015).

Kuehn, B. (2014) Driven by prescription drug abuse, heroin use increases among suburban and rural whites. FAMA 312: 118-119.

Lasich, C. (2013) Pharmacists refusing to fill prescriptions for pain relievers. Available at: http:/www.healthcentral.com/chronic- 
pain/c/240381/161487/refusing-prescriptions/ (accessed 6 January 2015).

McCabe, S., Cranford, J., Boyd, C. and Teter, C. (2007) Motives, diversion and routes of administration associated with nonmedical use of prescription opioids. Addict Behav 32: 562-575.

Morningstar (2013) Endo International PLC ENDP Q2 2013 earnings call transcript. Available at: http:// www.morningstar.com/earnings/56361440-endointernational-plc-q2-2013.aspx?pindex $=3$ (accessed 6 January 2015).

Muhuri, P., Gfroerer, J and Davies, M. (2013) Associations of nonmedical pain reliever use and initiation of heroin use in the United States. Available at: http://www.samhsa.gov/data/2k13/DataReview/ DR006/nonmedical-pain-reliever-use-2013.pdf (accessed 6 January 2015).

NIDA (2011a) Research report series: prescription drug abuse. Available at: http://www.drugabuse.gov/ sites/default/files/rxreportfinalprint.pdf (accessed 6 January 2015).

NIDA (2011b) Topics in brief: prescription drug abuse. Available at: http://www.drugabuse.gov/ publications/topics-in-brief/prescription-drug-abuse (accessed 6 January 2015).

NIDA (2014) Drugs, brains, and behavior: the science of addiction. Available at: http://www.drugabuse.gov/ publications/drugs-brains-behavior-science-addiction/ drugs-brain (accessed 6 January 2015).

NIH Medline Plus (2011) Opioids and chronic pain. NIH Medline Plus 6: 9.

ONDCP (2011). Epidemic: responding to America's prescription drug abuse crisis. Available at: http:// www.whitehouse.gov/sites/default/files/ondcp/issuescontent/prescription-drugs/rx_abuse_plan_0.pdf (accessed 6 January 2015).

ONDCP (2012) Fact sheet: cost benefits of investing early in substance abuse treatment. Available at: http://www.whitehouse.gov/sites/default/files/ondcp/ Fact_Sheets/investing_in_treatment_5-23-12.pdf (accessed 6 January 2015).

ONCDP (2013) National drug control strategy. Available at: http:/www.whitehouse.gov//sites/default/ files/ondcp/policy-and-research/ndcs_2013.pdf (accessed 6 January 2015).

ONDCP (2014) National drug control strategy. Available at: http://www.whitehouse.gov/sites/default/ files/ondcp/policy-and-research/ndcs_2014.pdf (accessed 6 January 2015).

PainDr.com (2013) Is Walgreens opiate policy deceptive? Available at: http://paindr.com/ is-walgreens-opiate-policy-deceptive/ (accessed 6 January 2015).
Partnership for Prescription Assistance (2014) Participating patient assistance programs. Available at: https://www.pparx.org/prescription_assistance_ programs/list_of_participating_programs (accessed 6 January 2015).

Perez, E., Dunnan, T. and Dana, F. (2014) Ready access, low cost, pill-like high: heroin's rise and fatal draw. Available at: http://www.cnn.com/2014/02/02/ us/heroin-use-rising/ (accessed 6 January 2015).

Pittman, D. (2012) FDA panel gives thumbs down to opioid. Available at: http://www.medpagetoday.com/ PainManagement/PainManagement/36334 (accessed 6 January 2015).

Pizzi, D. (2013) FDA approves one citizen petition, rejects another, clouding picture for abuse-deterrent opioid developers. Available at: http://www.painmedicinenews.com/ViewArticle. aspx?d=Policy $+\% 26+$ Management $\&$ d $\mathrm{id}=83 \& \mathrm{i}=$ June $+2013 \& \mathrm{i} \_\mathrm{id}=963 \& \mathrm{a} \_\mathrm{id}=23346$ (accessed 6 January 2015).

Rossiter, L., Kirson, N., Shei, A., White, A., Birnbaum, H., Ben-Joseph, R. et al. (2014) Medical cost savings associated with an extended-release opioid with abuse-deterrent technology in the U.S. $\mathcal{F}$ Med Econ 17: 279-287.

SAMHSA (2011) Results from the 2010 National Survey on Drug Use and Health. Available at: http:// www.samhsa.gov/data/nsduh/2k10nsduh/2k10results. htm (accessed 6 January 2015).

SAMHSA (2013a) Results from the 2012 national survey on drug use and health: summary of national findings. Available at: http://www.samhsa.gov/ data/NSDUH/2012SummNatFindDetTables/ NationalFindings/NSDUHresults2012.pdf (accessed 6 January 2015).

SAMHSA (2013b) Drug abuse warning network, 2011: national estimates of drug-related emergency department visits. Available at: http://www.samhsa. gov/data/2k13/DAWN2k11ED/DAWN2k11ED.htm (accessed 6 January 2015).

SAMHSA (2013c). Emergency department visits involving attention deficit/hyperactivity disorder stimulant medications. Available at: http://www. samhsa.gov/data/2k13/dawn073/sr073-addadhdmedications.htm (accessed 6 January 2015).

SAMSHA (2013d) Emergency department visits involving attention deficit/hyperactivity disorder stimulant medications. Available at: http://www. samhsa.gov/data/2k13/dawn073/sr073-addadhdmedications.htm (accessed 6 January 2015).

SAMSHA (2014b) Emergency department visits linked to zolpidem overmedication nearly doubled. Available at: http://www.samhsa.gov/newsroom/ advisories/1408111602.aspx (accessed 6 January 2015). 
Schaeffer, T. (2012) Abuse-deterrent formulations, an evolving technology against the abuse and misuse of opioid analgesics. F Med Toxicol 8: 400-407.

Severtson, S., Bartelson, B., Davis, J., Munoz, A., Schneider, M., Chilcoat, H. et al. (2013) Reduced abuse, therapeutic errors, and diversion following reformulation of extended-release oxycodone in 2010 . F Pain 14: 1122-1130.

Smith, S. and Kounang, N. (2013) Prescription drugs 'orphan' children in eastern Kentucky. Available at: http:/www.cnn.com/2012/12/14/health/kentuckyoverdoses/ (accessed 6 January 2015).

Surratt, H., Kurtz, S. and Cicero, T. (2011) Alternative routes of administration and risk for HIV among prescription opioid abusers. F Addict Dis 30: 334-341.

Thompson, E. (2013) New U.S. drug survey: marijuana and heroin increasing. Available at: http://www.cbsnews. $\mathrm{com} /$ news/new-us-drug-survey-marijuana-and-heroinincreasing/ (accessed 6 January 2015).

Turk, D., O’Connor, A., Dworkin, R., Chaudhry, A., Katz, N., Adams, E. et al. (2012) Research design considerations for clinical studies of abuse-deterrent opioid analgesics: IMMPACT recommendations.

Pain 153: 1997-2008.

Twillman, R. (2014) Tamper-deterrent opioid formulations: who needs them, and at what cost? Available at: http://www.aapainmanage.org/resources/ articles/tamper-deterrent-opioid-formulations-whoneeds-them-and-at-what-cost/ (accessed 6 January 2015).

Unick, G., Rosenblum, D., Mars, S. and Ciccarone, D. (2013) Intertwined epidemics: national demographic trends in hospitalizations for heroinand opioid-related overdoses, 1993-2009. Available at: http://www.plosone.org/article/fetchObject.actio n?uri=info \%3Adoi\%2F10.1371\%2Fjournal.pone.0 054496\&representation=PDF (accessed 6 January 2015).

Young, A., Havens, J. and Leukefeld, C. (2010)

Route of administration for illicit prescription opioids: a comparison of rural and urban drug users. Harm Reduct $\mathcal{F}$ 7: 24 .
Visit SAGE journals online http://taw.sagepub.com

@SAGE journals 